\title{
Desempenho Comparativo entre Países Exportadores de Pescado no Comércio Internacional: Brasil eficiente? ${ }^{1}$
}

\author{
Alessandra Cristina da Silva Farias² e Rafael Bráz Azevedo Farias ${ }^{3}$
}

\begin{abstract}
Resumo: O comércio internacional de pescados vem se destacando nas últimas décadas, pois é apontado como de ampla competição. Como forma de entender a dinâmica desse comércio, o objetivo da pesquisa foi caracterizar o desempenho histórico dos países exportadores de pescado no mercado internacional, com ênfase no Brasil, verificando quais países o comércio exterior serve como uma estratégia de crescimento econômico para os setores pesqueiro e aquícola. Para isso, uma matriz de desempenho foi elaborada de acordo com os valores e a tendência na série histórica mensuradas pelos índices de vantagem comparativa revelada (IVCR) e de posição relativa (IPR). Desse modo, a eficiência na dinâmica do comércio internacional de pescado se deve aos países desenvolvidos, que comercializam o pescado, principalmente entre si. Este intercâmbio é bem variado tanto em produtos quanto em países. No caso do Brasil, o desempenho foi ineficiente e decrescente, pois o pescado não é pauta importante no conjunto das exportações brasileiras, assim como a venda do produto para o mercado externo é inábil. Portanto, o pescado brasileiro não está servindo como uma estratégia de crescimento econômico para os setores pesqueiro e aquícola, utilizando-se do comércio internacional e interno.
\end{abstract}

Palavras-chaves: aquicultura, exportação, pesca, posição relativa, vantagem comparativa.

Abstract: The international trade of seafood has been expanding in the last decades, once it is pointed as of ample competition. As a way of understanding the dynamics of this trade, the objective of this research is to characterize the historical performance of seafood exporting countries in the international market, emphasizing Brazil, as well as verifying which countries foreign trade serves as a strategy of economic growth for the fishing sector and aquaculture. A performance matrix was elaborated according to the values and the trend in the historical series measured by the indices of comparative advantage revealed (IVCR) and relative position (IPR). It was verified that the efficiency of the dynamics of international trade of seafood is due to developed countries to the commercialization of fish mainly among them. In the case of Brazil, the performance was inefficient and decreasing, since fish is not an important factor in Brazilian exports as a whole, as well as the

1. Data de submissão: 23 de abril de 2017. Data de aceite: 25 de novembro de 2017.

2. Universidade Federal do Ceará. Fortaleza, Ceará, Brasil. E-mail: alesuite@gmail.com

3. Universidade Federal do Ceará. Fortaleza, Ceará, Brasil. E-mail: rafael@dema.ufc.br 
sale of the product to the foreign market is unskillful. Thus, the Brazilian seafood is not serving as a strategy of economic growth for the fishing and aquaculture sector, using international and domestic trade.

Key-words: aquaculture, exportation, fishing, relative position, comparative advantage.

Classificação JEL: Q27, F17.

DOI: http://dx.doi.org/10.1590/1234-56781806-94790560306

\section{Introdução}

A dinâmica do comércio internacional pode representar um elemento-chave sobre as condições de desenvolvimento de determinadas economias nacionais. Um país sujeito à influência do exterior pode utilizar-se do comércio internacional como um instrumento para o crescimento econômico, desde que tal atividade sirva de suporte para a ampliação da região exportadora (MUNDURUCA e SANTANA, 2012). Deste modo, a expansão das exportações é capaz de exercer um efeito multiplicador sobre as atividades do mercado interno, como o aumento e/ou a criação de serviços, gerando emprego e renda para a população.

Uma forma de entender a dinâmica do comércio exterior é verificar se um país possui vantagem comparativa de uma determinada commodity quando comparado a outros países, ou seja, é assumir que o país possa ser capaz de gerar retornos econômicos crescentes por meio de suas estruturas como: mão de obra, tecnologia e serviços para a produção e exportação.

Nesse contexto, o comércio internacional de pescados vem se destacando nas últimas décadas, pois está inserido entre as quatro maiores fontes de fornecimento de proteína animal para o consumo humano. Segundo a Organização das Nações Unidas para Agricultura e Alimentação (FAO, 2016), essa commodity representa, em média, $0,6 \%$ do total de produtos exportados no mundo. Os 10 maiores exportadores são: China, Noruega, Vietnã, Tailândia, Estados Unidos, Chile, Índia, Dinamarca, Holanda e Canadá, que juntas exportaram 37,6 milhões de toneladas (22\% do total), obtendo faturamento de 78 bilhões de dólares (53\% do total) em 2014.

Ressalta-se ainda, que o consumo per capita da última década apresentou tendência crescente, em que no ano 2005 foi de $16,5 \mathrm{~kg}$ e em 2014, de $20,1 \mathrm{~kg}$, o que significa um acréscimo no consumo de $22 \%$. Neste mesmo período, o setor produtivo de pescado mundial aumentou a produção em $17 \%$ e, para atender esta demanda crescente, a produção de pescado para o consumo humano aumentou $37 \%$. Por outro lado, a produção de pescado para o consumo não humano teve decréscimo de 41\% (FAO, 2010, 2016).

$\mathrm{Na}$ indústria mundial de pescados, dois sistemas de produção coexistem: a pesca extrativa, que é destinada à captura de recursos pesqueiros marinhos, estuarinos e continentais e a aquicultura, que é o cultivo de espécies aquáticas tanto em ambientes marinhos quanto dulcícolas. Dentre esses sistemas, a aquicultura tem se apresentado como a atividade mais expressiva em termos de produção dos últimos anos. Segundo a FAO (2016), em 2014, a aquicultura contribuiu com 73,8 milhões de toneladas, o que correspondeu a $44 \%$ da produção total no mundo. Esse aumento se deve à estagnação da pesca extrativa, em que $30 \%$ dos recursos pesqueiros mundiais estão sobre-explotados e $60 \%$, plenamente explotados.

De acordo com os relatórios do Departamento de Agricultura dos Estados Unidos (USDA, 2016) e da FAO (2016), no período de 2011 a 2015, o consumo médio de pescado no mundo foi de aproximadamente 
140 milhões de toneladas, que representa 37\% do total de carnes consumidas, ficando à frente do consumo de carne suína (27\%), de aves (21\%) e de carne bovina (15\%). Diante disso, 36\% do total de pescado produzido mundialmente em 2014 foi comercializado no mercado internacional sob a forma de diferentes produtos para o consumo humano (e.g. filé, congelado, resfriado, seco ou vivo). Esta proporção foi maior do que em meados da década de 1970, quando $25 \%$ da produção era exportada.

No Brasil, de acordo com o Sistema de Análise das Informações de Comércio Exterior (Aliceweb), a exportação de pescado no período de 2006 a 2016 contribuiu, em média, com $0,1 \%$ ao ano do total de todos os produtos exportados pelo Brasil (e.g. soja, combustíveis, minério de ferro, açúcar e café), o que correspondeu a aproximadamente 220 milhões de dólares/ano e exportação de 38 mil toneladas/ano. No contexto mundial, as exportações brasileiras participaram com $0,3 \%$ do total de pescado exportado.

Assim como no mundo, o consumo de pescado no Brasil também aumentou nos últimos anos. Em 1996, a média per capita foi de 7,5 kg e, em 2011, de 11,2 kg, com estimativa de $12 \mathrm{~kg}$ em 2015. Com isso, o Brasil está recorrendo às importações para atender à procura. Em 2015, a importação foi de 1,1 bilhão de dólares, principalmente de produtos que não são produzidos no Brasil, como o bacalhau, o salmão e a merluza (ROCHA et al., 2013), o que ocasionou déficit de $80 \%$ na balança comercial de pescado.

Apesar de a aquicultura ser atualmente a atividade econômica que mais cresceu no setor alimentício brasileiro, o País tem como principal pauta de exportação a lagosta, que é um crustáceo advindo da pesca extrativa marinha. Deste modo, questiona-se: o pescado brasileiro é um produto exportável? Serve como uma estratégia de crescimento econômico para os setores pesqueiro e aquícola, utilizando-se do comércio internacional?

Diante do exposto e levando-se em consideração que o comércio exterior de pescado é apontado como de ampla competição, o objetivo da pesquisa foi de caracterizar o desempenho histórico dos países exportadores de pescado no mercado internacional, com ênfase no Brasil, considerando os índices de vantagem comparativa revelada e o de posição relativa que inferem a importância e a eficiência da exportação de pescado para os países.

\section{Produção e exportação de pescado mundial}

Diante de um dos maiores desafios do mundo, como alimentar mais de 9 bilhões de pessoas até 2050 em um contexto de mudança climática, incerteza econômica e financeira e crescente competição por recursos naturais, a comunidade internacional elaborou um plano de desenvolvimento sustentável, a Agenda 2030. Esta agenda, dentre seus vários objetivos, tem o objetivo de contribuir e conduzir a pesca e a aquicultura para a segurança alimentar e a nutrição na utilização dos recursos naturais, de modo a garantir o desenvolvimento sustentável em termos econômicos, sociais e ambientais.

Com a produção da pesca extrativa estagnada desde o final dos anos 1980, a aquicultura tem sido responsável pelo impressionante crescimento da oferta de peixe para consumo humano. Em 1974, contribuiu com 7\%, em 1994, com $26 \%$ e, em 2014, com $44 \%$. A China tem desempenhado um papel importante neste crescimento, já que representa mais de $60 \%$ da produção mundial de aquicultura (FAO, 2016).

A divulgação de estudos sobre o valor nutricional do pescado que o associam às melhorias para a saúde tem causado, nos últimos anos, um aumento no consumo deste alimento. Dentre os possíveis benefícios da ingestão de uma ou duas porções de peixe por semana estão a redução do risco de acidente vascular cerebral, de depressão, de Alzheimer e de morte por doença cardíaca (SARTORI e AMANCIO, 2012). Além disso, o consumo de pescado também é influenciado por aspectos socioeconômicos e culturais.

O crescimento da oferta mundial de peixe para consumo humano ultrapassou o crescimento populacional nas últimas cinco décadas, aumentando a uma taxa média anual de 3,2\% no período de 1961-2013, o dobro do crescimento da população, resultando num aumento da disponibilidade média per capita. O consumo mundial per capita aumentou de 9,9 kg em média, na década de 1960, para 19,7 kg em 2014 (FAO, 2016). Além do aumento da produção, outros fatores que contribuíram para o aumento do consumo incluem reduções no desperdício, melhor utilização, melhores canais de distribuição e demanda aquecida ligada ao crescimento populacional, ao aumento dos rendimentos e à urbanização. O comércio internacional também desempenhou um papel importante no fornecimento de opções mais amplas aos consumidores. 
O pescado representa um dos segmentos mais comercializados do setor alimentar mundial, com cerca de $78 \%$ dos produtos destinados à concorrência do comércio internacional. Para muitos países, as exportações de pescado são essenciais para as suas economias. Em 2015, segundo a FAO (2016), 40\% do valor total das commodities comercializadas em Cabo Verde, Ilhas Faroe, Groenlândia, Islândia, Ilhas Maldivas, Ilhas Seichelles e Vanuatu correspondeu ao pescado. Globalmente, no mesmo ano, o comércio de pescado representou 9\% do total das exportações agrícolas e 1\% do comércio mundial de mercadorias.

Em relação aos principais países produtores de pescado no mundo, pertencem principalmente aos continentes europeu e asiático, com destaque para a China, tanto em pesca extrativa marinha $(18,2 \%)$ quanto continental $(24,1 \%)$ e em aquicultura $(61,6 \%)$ (Quadro 1).
O mesmo se observa nas exportações e importações, tendo a China e a Noruega como os maiores exportadores e os EUA e o Japão como os maiores importadores (Quadro 1).

Uma parte considerável e crescente do consumo de peixe nos países desenvolvidos consiste em importações, devido à procura estável e à produção estagnada da pesca extrativa. Nos países em desenvolvimento, onde o consumo de peixe tende a se basear em produtos localmente disponíveis, o consumo é impulsionado mais pela oferta do que pela demanda, como pode ser observado no Brasil, em que os consumidores estão experimentando uma diversificação dos tipos de pescado disponíveis por meio de um aumento nas importações.

Desse modo, nas últimas décadas, têm-se observado mudanças expressivas associadas com o nível de

Quadro 1. Principais países que produziram, exportaram e importaram pescado em 2014

\begin{tabular}{|c|c|c|c|c|c|}
\hline \multicolumn{2}{|c|}{ Pesca marinha $(t)$} & \multicolumn{2}{|c|}{ Pesca continental (t) } & \multicolumn{2}{|c|}{ Pescado (US\$ x 10 ${ }^{3}$ ) } \\
\hline País & Produção & País & Produção & País & Exportação \\
\hline China & 14.811 .390 & China & 2.295 .157 & China & 20.980 \\
\hline Indonésia & 6.016 .525 & Mianmar & 1.381 .030 & Noruega & 10.803 \\
\hline EUA & 4.954 .467 & Índia & 1.300 .000 & Vietnã & 8.029 \\
\hline Rússia & 4.000702 & Bangladesh & 995.805 & Tailândia & 6.565 \\
\hline Japão & 3.630 .364 & Camboja & 505.005 & EUA & 6.144 \\
\hline Peru & 3.548 .689 & Uganda & 461.196 & Chile & 5.854 \\
\hline Índia & 3.418 .821 & Indonésia & 420.190 & Índia & 5.604 \\
\hline Vietnã & 2.711 .100 & Nigéria & 354.466 & Dinamarca & 4.765 \\
\hline Mianmar & 2.702 .240 & Tanzânia & 278.933 & Países Baixo & 4.555 \\
\hline Noruega & 2.301 .288 & Egito & 236.992 & Canadá & 4.503 \\
\hline Chile & 2.175 .486 & Brasil & 235.527 & Espanha & 3.995 \\
\hline Filipinas & 2.137 .350 & Rússia & 224.854 & Subtotal & 81.796 \\
\hline Coréia do Sul & 1.718 .626 & Subtotal & 9.540 .591 & Total ${ }^{*}$ & 148.147 \\
\hline Tailândia & 1.559 .746 & Total $^{*}$ & 11.895 .881 & País & Importação \\
\hline Malásia & 1.458 .126 & \multicolumn{2}{|c|}{ Aquicultura $(\mathrm{t})$} & EUA & 20.317 \\
\hline México & 1.396 .205 & País & Produção & Japão & 14.844 \\
\hline Marrocos & 1.350 .147 & China & 45.469 .000 & China & 8.501 \\
\hline Espanha & 1.103 .537 & Índia & 4.881 .000 & Espanha & 7.051 \\
\hline Islândia & 1.076 .558 & Indonésia & 4.253 .900 & França & 6.670 \\
\hline Taiwan & 1.068 .244 & Vietnã & 3.397 .100 & Alemanha & 6.205 \\
\hline Canada & 835.196 & Bangladesh & 1.956 .900 & Itália & 6.166 \\
\hline Argentina & 815.355 & Noruega & 1.332 .500 & Suíça & 4.783 \\
\hline Reino Unido & 754.992 & Chile & 1.214 .500 & Reino Unido & 4.638 \\
\hline Dinamarca & 745.019 & Egito & 1.137 .100 & Coréia & 4.271 \\
\hline Equador & 663.439 & Nigéria & 313.200 & Hong Kong & 3.201 \\
\hline Subtotal & 66.953 .612 & Subtotal & 63.988 .400 & Subtotal & 86.648 \\
\hline Total $^{*}$ & 81.549 .353 & Total $^{*}$ & 73.783 .700 & Total $^{*}$ & 140.616 \\
\hline
\end{tabular}

* Total referente ao mundo.

Fonte: FAO (2016). 
competitividade do comércio internacional e local de pescado, que está se tornando mais complexo, dinâmico e altamente segmentado com maior diversificação de espécies e formas de produtos. Portanto, para que determinado país continue operando com eficiência é necessário se adaptar as essas novas características do setor.

\section{Teoria do comércio internacional}

As teorias do comércio internacional têm como princípio básico as vantagens comparativas. O comércio entre nações existe se estas apresentarem vantagens com a negociação de um produto, utilizando o fator de produção mais abundante. Portanto, seria importado o bem que fosse produzido a custos maiores e exportado o bem produzido a custos comparativos mais baixos, quando comparado a outras economias. A literatura econômica considera, ainda, que o comércio exterior e a competitividade de um país são afetados por um conjunto de variáveis, como taxa de câmbio, preços, custos dos fatores, qualidade do produto, serviços, mão de obra, entre outras (MOREIRA, 2012).

A importância do comércio exterior no processo de crescimento econômico de um determinado país é geralmente destacada pela Teoria da Base de Exportação, proposta inicialmente por Douglas North, em 1955. A ideia é que o crescimento das exportações (atividade básica) gera um efeito multiplicador e de aceleração no setor de mercado interno, criando demanda por serviços, como transportes, comunicações e financiamentos.

Nessa condição, a possibilidade de aumentar as exportações surge como uma alternativa para a elevação da demanda efetiva, minimizando ou afastando as crises e possibilitando a absorção da oferta de produtos locais pelo mercado global. Assim, uma região ou país que consiga produzir bens com longo alcance, suportando o aumento da complexidade interna de sua economia, pode conquistar novos mercados. Nesse processo, são geradas economias de escala e maior eficiência produtiva, o que reduz os custos médios da economia, estimulando a acumulação do capital e o aumento do nível de emprego (GONÇALVES et al., 2013).

As teorias para a compreensão da competividade no comércio internacional tiveram uma nova conotação a partir da Teoria das Vantagens Comparativas
Reveladas proposta por Bela Balassa, em 1965. Essa teoria tem como objetivo identificar para quais commodities um país apresenta vantagem comparativa na produção e na exportação. Nessa teoria, a vantagem comparativa é considerada revelada, pois sua quantificação se baseia em dados ex post.

Soma-se à essa teoria a ideia de Lafay et al. (1999), com a proposta de determinar a posição de um país no mercado internacional com relação a um determinado produto, verificando se esse país possui parcela de mercado dentro de um ambiente competitivo entre os países que o produzem. Para isso é necessário incluir nos cálculos o saldo comercial em relação ao total desse produto comercializado no mundo, em um determinado período.

Esta medida de competição internacional entre países é principalmente influenciada pelas variáveis macroeconômicas, pelo peso da economia do país em relação ao mundo, pelas características estruturais do consumo e da produção do bem e pelas distorções que podem ser introduzidas pelo poder público, tais como a subvenção às exportações e/ou a geração de barreiras ao processo de importação (LAFAY et al., 1999).

Assim, a estimativa desses índices de desempenho pode ser uma fonte complementar de subsídios para o estabelecimento de políticas públicas setoriais e de estratégias para as empresas de determinado setor produtivo.

\section{Metodologia}

\subsection{Fonte dos dados}

Os dados utilizados neste trabalho, referentes ao período de 2001 a 2016, foram adquiridos no site de estatísticas de comércio exterior mundial, intitulado "Internacional Trade Centre (ITC) - Market Analysis Tools - Trade Map".

O ITC funciona com diferentes variáveis de consulta, a principal utilizada foi o código de Nomenclatura Comum do Mercosul (NCM), para que fosse possível extrair somente as informações de pescados. Este código é composto por até oito dígitos, sendo os seis primeiros formados pelo Sistema Harmonizado (capítulo, posição e subposição), e os dois últimos números (item e subitem) são criados de acordo com a definição estabelecida entre os países do Mercosul. Deste modo, 
o capítulo que representa o pescado é o de número 03, que é intitulado de "Peixes e crustáceos, moluscos e outros invertebrados aquáticos".

No capítulo 03 foram filtradas as informações de valor, expresso em dólares dos Estados Unidos, na condição de venda FOB (Free on board) por ano das exportações e importações dos países que apresentaram a série histórica completa, assim como os valores das exportações e importações de todos os produtos comercializados no mundo.

\subsection{Análise dos dados}

Inicialmente, a análise de desempenho dos países exportadores no comércio exterior de pescado foi realizada com base em dois índices: Índice de Vantagem Comparativa Revelada (IVCR) e Índice de Posição Relativa (IPR). Posteriormente, foi elaborada uma matriz de desempenho, com a finalidade caracterizar e agrupar os países de acordo com os valores e a tendência na série histórica mensuradas pelo IVCR e IPR.

\section{3. Índice de Vantagem Comparativa Revelada (IVCR)}

O conceito de vantagem comparativa procura mostrar que o comércio internacional é vantajoso quando os países se dedicam a produzir apenas aqueles bens em que são comparativamente mais eficientes do que outros países. Desse modo, procura-se mensurar o desempenho do país exportador com base em uma série temporal, identificando sua eficiência produtiva relativa no comércio internacional (PAIS et al., 2008).

O índice utilizado para verificar esse desempenho foi o proposto por Balassa (1965), conhecido como o índice de vantagem comparativa revelada (IVCR). A equação que define este índice é a seguinte:

$$
I V C R=\frac{\frac{X_{i j}}{X_{i}}}{\frac{X_{w j}}{X_{w}}}
$$

Em que: $i$ é o país; $j$ é o pescado; $X_{i j}$ é o valor da exportação do produto $j$ pelo país $i ; X_{i}$ é o valor total das exportações do país $i ; X_{w j}$ é o valor total das exportações do produto $j$ no mundo e $X_{w}$ é o valor total das exportações no mundo.
Desse modo, se o IVCR for maior que 1, significa que o país $i$ tem vantagem comparativa revelada para as exportações de pescado e, se o IVCR for menor que 1 , o país $i$ tem desvantagem comparativa revelada para as exportações de pescado.

\section{4. Índice de Posição Relativa (IPR)}

O índice de posição relativa consiste em mensurar a participação no saldo comercial (exportações menos importações) de uma determinada nação no mercado mundial de certo produto, indicando, assim, a sua eficiência nas exportações.

Em termos de resultados, o IPR poderá mostrar se as exportações/importações líquidas de um determinado país estão crescendo a taxas superiores ou inferiores às do comércio mundial. A equação que define este índice foi o proposto por Lafay et al. (1999), sendo:

$$
I P R=100 \cdot \frac{X_{i j}-M_{i j}}{X_{w j}+M_{w j}}
$$

Em que: $i$ é o país; $j$ é o pescado; $X_{i j}$ é o valor da exportação do produto $j$ pelo país $i ; M_{i j}$ é o valor das importações do produto $j$ pelo país $i ; X_{w j}$ é o valor total das exportações do produto $j$ no mundo; $M_{w j}$ é o valor total das importações do produto $j$ no mundo.

Quanto maior o valor do IPR, maior será a intensidade de participação do produto doméstico no comércio internacional. Se o indicador for positivo, o país será um exportador líquido; se for negativo, será um importador líquido (ESPERANÇA et al., 2011).

\subsection{Tendência linear da série histórica dos índices IVCR e IPR}

A análise de tendência de uma série temporal histórica pode ser realizada de diversas maneiras. Neste texto foi realizada uma análise de tendência linear, que pode ser crescente, decrescente ou estável. Para isso, à cada série dos índices IVCR e IPR de cada país, foram ajustadas uma equação da reta através do método dos mínimos quadrados (GUJARATI e PORTER, 2011), ou seja, foram ajustados os seguintes modelos de regressão linear:

$$
\begin{aligned}
& \mathrm{IPR}=\alpha_{\mathrm{IPR}}+\beta_{\mathrm{IPR}} t \\
& \mathrm{e} \\
& \mathrm{IVCR}=\alpha_{\mathrm{IVCR}}+\beta_{\mathrm{IVCR}} t
\end{aligned}
$$


Em que: $t$ denota o tempo (em anos); $\alpha_{\text {IPR }}$ e $\alpha_{\text {IVCR }}$ são os coeficientes lineares (intercepto) e $\beta_{\text {IPR }}$ e $\beta_{\text {IVCR }}$ são os coeficientes angulares (inclinação) das retas de regressão ajustadas aos índices IPR e ICVR, respectivamente.

Após o ajuste, foi verificado se os valores dos coeficientes angulares ( $\beta$-beta) podem ou não serem considerados iguais a zero. Para isto, foi utilizado o teste $t$ de Student, com nível de significância de 5\% (GUJARATI e PORTER, 2011). Deste modo, se $\beta$ for considerado igual a zero, o índice (IPR ou IVCR) apresenta comportamento estável; por outro lado, se $\beta$ for considerado diferente de zero, o índice pode apresentar comportamento crescente $(\beta>0)$ ou decrescente $(\beta<0)$.

\subsection{Matriz de desempenho dos países exportadores de pescado no comércio internacional}

Como forma de relacionar os índices de desempenho IVCR e IPR, uma matriz foi construída com o intuito de caracterizar os países quanto ao seu desempenho no mercado internacional, classificando-os em:

- Eficiente: é o país eficiente no comércio exterior, apresentando o pescado como pauta importante no contexto das exportações do país (IVCR > 1), assim como eficiência na venda do produto para o mercado externo (IPR $>0$ ).

- Com potencial externo: é o país em que o pescado se apresenta como pauta importante no contexto das exportações do país (IVCR > 1), mas que, no entanto, precisa avançar na eficiência da venda do pescado para o mercado externo (IPR < 0). Sendo assim, é um país com potencial para obter melhor posição relativa no comércio exterior.

- Com potencial interno: é o país em que há eficiência na venda do produto para o mercado externo (IPR > 0), mas que, no entanto, precisa obter melhores resultados na pauta de exportação (IVCR < 1). Sendo assim, é um país com potencial para apresentar melhor vantagem comparativa.

- Ineficiente: é o país ineficiente no comércio exterior, em que o pescado não é pauta importante no contexto das exportações do país (IVCR $<1$ ), e é ineficiente na venda do produto para o mercado externo (IPR $<0$ ).

Em cada classificação citada anteriormente, os países ainda foram agrupados de acordo com a tendência da série histórica dos valores de IVCR e IPR (Quadro 2). Para isso, foi utilizada a análise de regressão linear. Inicialmente, foi verificado, utilizando o teste $t$ de Student, se o valor do coeficiente angular $(\beta)$, que indica a inclinação da reta, pode ser considerado igual a zero ao nível de 5\% de significância. Posteriormente, a tendência foi classificada em:

- Crescente: em que o sinal do coeficiente angular ( $\beta$-beta) é positivo e pode ser considerado diferente de zero.

- Estável: em que o coeficiente angular ( $\beta$-beta), independente do sinal, pode ser considerado igual a zero.

- Decrescente: em que o sinal do coeficiente angular ( $\beta$-beta) é negativo e pode ser considerado diferente de zero.

Quadro 2. Matriz de desempenho dos países exportadores de pescado

\begin{tabular}{|c|c|c|c|c|c|c|}
\hline \multirow{2}{*}{$\begin{array}{c}\text { Índices e } \\
\text { tendências }\end{array}$} & \multicolumn{1}{|c|}{ IPR $>0$} & \multicolumn{2}{c|}{ IPR $<0$} \\
\hline
\end{tabular}

Fonte: Elaborado pelos autores. 


\section{Resultados}

O desempenho dos exportadores de pescado foi avaliado para 143 países que foram organizados em ordem decrescente do valor das exportações ocorridas em 2016. Assim, para cada país foram registrados a média, o desvio padrão dos índices IVCR e IPR e a tendência destes valores ao longo dos anos, de acordo com o valor do coeficiente angular $(\beta)$ da reta de regressão e sua significância estatística ( $p$-valor) (Tabela 1).
De acordo com os resultados, os valores médios do IVCR variaram de zero a 152,897. Dos 143 países avaliados, 75 apresentaram IVCR $>1,0$, o que significa dizer que, para 52,4\% dos países exportadores, o pescado é pauta importante nas exportações, apresentando vantagem comparativa. Dentre estes países, destacam-se a predominância de países insulares: Islândia, Ilhas Feroe, Groelândia, Ilhas Malvinas, Maldivas, Santa Helena, Terras Austrais e São Pedro e Miquelon, que apresentaram IVCR > 40,0. Em relação à tendência temporal, 35 países mostraram valores do IVCR crescentes, 57, estáveis e 51, decrescentes.

Tabela 1. Índice de vantagem comparativa revelada (IVCR) e Índice de Posição relativa (IPR) dos países exportadores de pescado em relação ao mundo, no período de 2001 a 2016

\begin{tabular}{|c|c|c|c|c|c|c|c|c|}
\hline \multirow{2}{*}{ País } & \multicolumn{4}{|c|}{ IVCR } & \multicolumn{4}{|c|}{ IPR } \\
\hline & Média & Desvpad & $\beta$ & $p$-valor & Média & Desvpad & $\beta$ & $p$-valor \\
\hline China & 1,053 & 0,169 & $-0,021$ & 0,033 & 2,056 & 0,937 & 0,178 & 0,000 \\
\hline Noruega & 9,756 & 1,953 & 0,399 & 0,000 & 3,936 & 0,626 & 0,125 & 0,000 \\
\hline Estados Unidos de América & 0,624 & 0,058 & $-0,006$ & 0,112 & $-5,175$ & 0,626 & 0,103 & 0,002 \\
\hline Vietnã & 11,808 & 3,936 & $-0,860$ & 0,000 & 2,078 & 0,163 & 0,017 & 0,081 \\
\hline Índia & 2,567 & 0,789 & $-0,089$ & 0,057 & 1,454 & 0,525 & 0,077 & 0,007 \\
\hline Canadá & 1,561 & 0,086 & 0,000 & 0,931 & 1,258 & 0,349 & $-0,069$ & 0,000 \\
\hline Chile & 9,537 & 1,406 & $-0,113$ & 0,188 & 1,800 & 0,212 & 0,030 & 0,010 \\
\hline Suécia & 2,222 & 1,112 & 0,246 & 0,000 & $-0,289$ & 0,072 & $-0,006$ & 0,176 \\
\hline Espanha & 1,874 & 0,153 & $-0,013$ & 0,149 & $-2,075$ & 0,599 & 0,119 & 0,000 \\
\hline Rússia & 0,673 & 0,343 & 0,058 & 0,001 & 0,737 & 0,465 & 0,089 & 0,000 \\
\hline Indonésia & 3,044 & 0,457 & $-0,078$ & 0,001 & 1,260 & 0,142 & $-0,016$ & 0,064 \\
\hline Países Baixos & 0,900 & 0,077 & 0,008 & 0,099 & 0,374 & 0,124 & $-0,015$ & 0,033 \\
\hline Equador & 12,499 & 3,632 & 0,633 & 0,001 & 0,609 & 0,302 & 0,058 & 0,000 \\
\hline Dinamarca & 4,169 & 0,333 & $-0,053$ & 0,003 & 0,502 & 0,139 & $-0,030$ & 0,000 \\
\hline Reino Unido & 0,714 & 0,098 & 0,011 & 0,059 & $-0,384$ & 0,166 & 0,009 & 0,376 \\
\hline Tailândia & 2,834 & 0,843 & $-0,177$ & 0,000 & 0,347 & 0,433 & $-0,088$ & 0,000 \\
\hline Alemanha & 0,175 & 0,034 & 0,007 & 0,000 & $-1,346$ & 0,098 & $-0,001$ & 0,880 \\
\hline Islândia & 69,554 & 8,693 & $-1,303$ & 0,006 & 0,975 & 0,133 & $-0,025$ & 0,000 \\
\hline Taipei Chino & 1,108 & 0,189 & $-0,029$ & 0,004 & 0,647 & 0,242 & $-0,047$ & 0,000 \\
\hline Argentina & 3,916 & 0,579 & $-0,076$ & 0,022 & 0,752 & 0,102 & $-0,014$ & 0,017 \\
\hline Japão & 0,283 & 0,053 & 0,010 & 0,000 & $-7,447$ & 2,343 & 0,495 & 0,000 \\
\hline França & 0,481 & 0,053 & $-0,002$ & 0,483 & $-1,830$ & 0,135 & 0,005 & 0,594 \\
\hline Coréia do Sul & 0,570 & 0,118 & $-0,019$ & 0,003 & $-0,931$ & 0,170 & $-0,004$ & 0,739 \\
\hline Polônia & 0,888 & 0,224 & 0,043 & 0,000 & $-0,190$ & 0,042 & $-0,006$ & 0,006 \\
\hline Marrocos & 9,579 & 1,851 & $-0,326$ & 0,001 & 0,492 & 0,112 & $-0,018$ & 0,003 \\
\hline Austrália & 1,168 & 0,469 & $-0,099$ & 0,000 & 0,219 & 0,169 & $-0,034$ & 0,000 \\
\hline Nova Zelândia & 5,801 & 0,651 & $-0,120$ & 0,000 & 0,548 & 0,064 & $-0,013$ & 0,000 \\
\hline Ilhas Feroe & 151,573 & 15,923 & 2,483 & 0,004 & 0,465 & 0,062 & 0,005 & 0,206 \\
\hline México & 0,465 & 0,054 & $-0,009$ & 0,002 & 0,247 & 0,123 & $-0,024$ & 0,000 \\
\hline Portugal & 2,074 & 0,534 & 0,100 & 0,000 & $-0,668$ & 0,159 & 0,030 & 0,000 \\
\hline Bélgica & 0,381 & 0,054 & $-0,003$ & 0,350 & $-0,435$ & 0,032 & 0,004 & 0,039 \\
\hline Hong Kong, China & 0,228 & 0,040 & 0,001 & 0,604 & $-1,239$ & 0,106 & 0,009 & 0,184 \\
\hline Peru & 2,932 & 0,317 & 0,016 & 0,419 & 0,232 & 0,065 & 0,013 & 0,000 \\
\hline Turquia & 0,526 & 0,116 & 0,022 & 0,000 & 0,127 & 0,042 & 0,008 & 0,000 \\
\hline Grécia & 4,114 & 0,672 & 0,028 & 0,502 & 0,079 & 0,079 & 0,016 & 0,000 \\
\hline Namíbia & 25,085 & 4,904 & $-0,772$ & 0,003 & 0,325 & 0,043 & 0,001 & 0,683 \\
\hline Bangladesh & 6,446 & 2,543 & $-0,474$ & 0,000 & 0,327 & 0,057 & $-0,005$ & 0,114 \\
\hline
\end{tabular}




\begin{tabular}{|c|c|c|c|c|c|c|c|c|}
\hline \multirow{2}{*}{ País } & \multicolumn{4}{|c|}{ IVCR } & \multicolumn{4}{|c|}{ IPR } \\
\hline & Média & Desvpad & $\beta$ & $p$-valor & Média & Desvpad & $\beta$ & $p$-valor \\
\hline Irlanda & 0,711 & 0,132 & 0,023 & 0,001 & 0,222 & 0,048 & $-0,008$ & 0,004 \\
\hline Malásia & 0,574 & 0,105 & $-0,002$ & 0,801 & $-0,028$ & 0,073 & $-0,010$ & 0,011 \\
\hline Filipinas & 1,295 & 0,165 & 0,022 & 0,021 & 0,146 & 0,066 & $-0,012$ & 0,000 \\
\hline Itália & 0,193 & 0,031 & $-0,002$ & 0,257 & $-2,225$ & 0,227 & 0,035 & 0,004 \\
\hline Lituânia & 1,579 & 0,443 & 0,090 & 0,000 & $-0,040$ & 0,023 & 0,001 & 0,359 \\
\hline África do Sul & 1,293 & 0,364 & $-0,075$ & 0,000 & 0,204 & 0,077 & $-0,016$ & 0,000 \\
\hline Honduras & 11,985 & 5,341 & 0,607 & 0,053 & 0,109 & 0,060 & 0,011 & 0,000 \\
\hline Senegal & 25,581 & 10,756 & $-0,802$ & 0,225 & 0,168 & 0,065 & $-0,004$ & 0,330 \\
\hline Groenlândia & 112,616 & 9,708 & 1,587 & 0,002 & 0,177 & 0,032 & $-0,005$ & 0,002 \\
\hline Nicarágua & 14,568 & 5,163 & $-0,680$ & 0,021 & 0,087 & 0,028 & 0,005 & 0,000 \\
\hline Singapura & 0,209 & 0,091 & $-0,019$ & 0,000 & $-0,206$ & 0,063 & $-0,011$ & 0,001 \\
\hline Tanzânia & 12,295 & 5,678 & $-1,164$ & 0,000 & 0,108 & 0,027 & $-0,004$ & 0,020 \\
\hline Brasil & 0,398 & 0,275 & $-0,056$ & 0,000 & $-0,216$ & 0,289 & $-0,060$ & 0,000 \\
\hline Sri Lanka & 3,681 & 0,695 & 0,067 & 0,111 & 0,053 & 0,012 & 0,000 & 0,784 \\
\hline Estônia & 2,126 & 0,262 & $-0,025$ & 0,104 & 0,019 & 0,010 & 0,000 & 0,878 \\
\hline Croácia & 2,036 & 0,291 & 0,006 & 0,725 & 0,022 & 0,014 & 0,001 & 0,086 \\
\hline Ilhas Malvinas & 152,897 & 19,963 & 1,678 & 0,167 & 0,098 & 0,016 & $-0,001$ & 0,227 \\
\hline Colômbia & 1,024 & 0,446 & $-0,095$ & 0,000 & 0,052 & 0,060 & $-0,013$ & 0,000 \\
\hline Omã & 0,661 & 0,308 & $-0,022$ & 0,243 & 0,047 & 0,041 & 0,001 & 0,703 \\
\hline Malta & 5,134 & 2,795 & 0,317 & 0,054 & 0,025 & 0,014 & 0,001 & 0,122 \\
\hline Tunísia & 1,952 & 0,458 & $-0,069$ & 0,006 & 0,065 & 0,025 & $-0,005$ & 0,000 \\
\hline Mauricio & 5,566 & 2,180 & 0,403 & 0,000 & $-0,092$ & 0,034 & $-0,004$ & 0,055 \\
\hline Maldivas & 135,093 & 43,653 & 6,780 & 0,004 & 0,054 & 0,015 & 0,000 & 0,793 \\
\hline República Checa & 0,123 & 0,008 & 0,000 & 0,359 & 0,048 & 0,009 & 0,002 & 0,000 \\
\hline Bielorrússia & 0,192 & 0,236 & 0,040 & 0,001 & $-0,145$ & 0,030 & 0,000 & 0,994 \\
\hline Uganda & 18,060 & 7,919 & $-1,592$ & 0,000 & 0,079 & 0,017 & $-0,003$ & 0,001 \\
\hline Coréia do Norte & 15,265 & 15,409 & $-2,504$ & 0,002 & 0,083 & 0,101 & $-0,017$ & 0,001 \\
\hline Uruguai & 5,664 & 1,980 & $-0,389$ & 0,000 & 0,082 & 0,021 & $-0,004$ & 0,000 \\
\hline Costa Rica & 2,217 & 0,618 & $-0,106$ & 0,001 & 0,045 & 0,027 & $-0,005$ & 0,000 \\
\hline Letônia & 1,592 & 0,465 & 0,062 & 0,019 & $-0,013$ & 0,007 & $-0,001$ & 0,000 \\
\hline Arábia Saudita & 0,040 & 0,020 & 0,002 & 0,199 & $-0,095$ & 0,045 & $-0,007$ & 0,008 \\
\hline Madagascar & 17,047 & 6,964 & $-1,324$ & 0,000 & 0,064 & 0,038 & $-0,008$ & 0,000 \\
\hline Guiana & 15,147 & 4,522 & $-0,832$ & 0,000 & 0,045 & 0,012 & $-0,002$ & 0,000 \\
\hline Venezuela & 0,254 & 0,242 & $-0,035$ & 0,009 & $-0,005$ & 0,074 & $-0,009$ & 0,032 \\
\hline Ilhas Marshall & 26,809 & 14,178 & $-0,099$ & 0,912 & 0,053 & 0,019 & 0,001 & 0,424 \\
\hline Quênia & 2,467 & 1,034 & $-0,197$ & 0,000 & 0,030 & 0,014 & $-0,003$ & 0,000 \\
\hline Trinidade e Tobago & 0,327 & 0,206 & 0,026 & 0,030 & 0,002 & 0,007 & 0,001 & 0,221 \\
\hline Cuba & 5,308 & 1,811 & $-0,289$ & 0,003 & 0,035 & 0,019 & $-0,003$ & 0,001 \\
\hline Bahamas & 28,305 & 10,505 & $-1,699$ & 0,002 & 0,051 & 0,023 & $-0,005$ & 0,000 \\
\hline Cazaquistão & 0,235 & 0,059 & $-0,003$ & 0,360 & 0,016 & 0,011 & 0,000 & 0,968 \\
\hline Guatemala & 1,037 & 0,418 & 0,027 & 0,303 & 0,005 & 0,012 & $-0,001$ & 0,043 \\
\hline Cabo Verde & 28,308 & 29,202 & 2,290 & 0,200 & 0,013 & 0,011 & 0,002 & 0,000 \\
\hline Belize & 22,461 & 12,119 & $-0,173$ & 0,821 & 0,024 & 0,014 & $-0,001$ & 0,566 \\
\hline Moçambique & 7,824 & 6,625 & $-1,351$ & 0,000 & 0,032 & 0,044 & $-0,010$ & 0,000 \\
\hline Finlândia & 0,075 & 0,034 & 0,007 & 0,000 & $-0,105$ & 0,025 & $-0,005$ & 0,000 \\
\hline Chipre & 2,675 & 1,339 & 0,059 & 0,482 & $-0,014$ & 0,005 & 0,000 & 0,931 \\
\hline Egito & 0,103 & 0,052 & 0,010 & 0,000 & $-0,158$ & 0,080 & $-0,016$ & 0,000 \\
\hline Hungria & 0,029 & 0,014 & 0,002 & 0,013 & $-0,014$ & 0,005 & 0,000 & 0,502 \\
\hline Bulgária & 0,180 & 0,024 & 0,002 & 0,146 & $-0,014$ & 0,007 & $-0,001$ & 0,000 \\
\hline Bahrein & 0,268 & 0,069 & $-0,001$ & 0,836 & 0,004 & 0,003 & $-0,001$ & 0,001 \\
\hline Somália & 7,046 & 6,384 & $-1,021$ & 0,003 & 0,005 & 0,004 & 0,000 & 0,186 \\
\hline Áustria & 0,015 & 0,009 & 0,002 & 0,000 & $-0,130$ & 0,016 & $-0,003$ & 0,003 \\
\hline Albânia & 0,911 & 0,449 & 0,075 & 0,001 & $-0,007$ & 0,004 & 0,000 & 0,839 \\
\hline Romênia & 0,036 & 0,017 & 0,003 & 0,000 & 0,003 & 0,002 & 0,000 & 0,611 \\
\hline
\end{tabular}


460 - Desempenho Comparativo entre Países Exportadores de Pescado no Comércio Internacional: Brasil eficiente?

\begin{tabular}{|c|c|c|c|c|c|c|c|c|}
\hline \multirow{2}{*}{ País } & \multicolumn{4}{|c|}{ IVCR } & \multicolumn{4}{|c|}{ IPR } \\
\hline & Média & Desvpad & $\beta$ & p-valor & Média & Desvpad & $\beta$ & p-valor \\
\hline Santa Helena & 86,410 & 20,656 & 2,743 & 0,020 & 0,007 & 0,002 & 0,000 & 0,978 \\
\hline Polinésia Francesa & 9,513 & 5,808 & 0,892 & 0,005 & $-0,001$ & 0,004 & 0,000 & 0,417 \\
\hline Haiti & 1,807 & 0,330 & 0,024 & 0,246 & $-0,005$ & 0,002 & 0,000 & 0,002 \\
\hline Nova Caledônia & 3,973 & 1,963 & $-0,382$ & 0,000 & 0,014 & 0,007 & $-0,001$ & 0,000 \\
\hline Armênia & 1,430 & 1,172 & 0,211 & 0,000 & 0,004 & 0,004 & 0,001 & 0,004 \\
\hline Samoa & 21,380 & 7,963 & $-0,354$ & 0,478 & 0,005 & 0,004 & $-0,001$ & 0,002 \\
\hline Israel & 0,048 & 0,018 & 0,001 & 0,459 & $-0,104$ & 0,042 & $-0,007$ & 0,003 \\
\hline Ucrânia & 0,069 & 0,048 & $-0,004$ & 0,204 & $-0,231$ & 0,122 & $-0,017$ & 0,013 \\
\hline Jamaica & 1,114 & 0,277 & 0,032 & 0,048 & $-0,033$ & 0,006 & 0,001 & 0,001 \\
\hline Costa do Marfim & 0,195 & 0,169 & $-0,007$ & 0,485 & $-0,183$ & 0,025 & $-0,001$ & 0,437 \\
\hline Luxemburgo & 0,148 & 0,038 & 0,005 & 0,023 & $-0,040$ & 0,001 & 0,000 & 0,145 \\
\hline Ilhas Menores & 18,819 & 9,866 & $-0,223$ & 0,720 & $-0,042$ & 0,019 & 0,003 & 0,009 \\
\hline Terras Austrais Francesas & 40,505 & 27,591 & 1,931 & 0,256 & $-0,004$ & 0,017 & 0,000 & 0,786 \\
\hline Eslovênia & 0,029 & 0,017 & 0,002 & 0,016 & $-0,025$ & 0,003 & 0,000 & 0,542 \\
\hline Geórgia & 0,330 & 0,273 & 0,025 & 0,132 & $-0,012$ & 0,007 & $-0,001$ & 0,000 \\
\hline El Salvador & 0,731 & 0,444 & $-0,091$ & 0,000 & $-0,005$ & 0,018 & $-0,003$ & 0,005 \\
\hline Argélia & 0,034 & 0,013 & $-0,002$ & 0,001 & $-0,018$ & 0,015 & $-0,003$ & 0,000 \\
\hline Eslováquia & 0,025 & 0,010 & 0,000 & 0,645 & $-0,021$ & 0,003 & 0,000 & 0,010 \\
\hline Granada & 24,944 & 8,980 & 1,403 & 0,004 & 0,002 & 0,001 & 0,000 & 0,290 \\
\hline Suíça & 0,004 & 0,001 & 0,000 & 0,471 & $-0,273$ & 0,008 & 0,000 & 0,557 \\
\hline Malaui & 0,130 & 0,151 & 0,002 & 0,863 & $-0,001$ & 0,004 & 0,000 & 0,145 \\
\hline Jordânia & 0,078 & 0,062 & 0,005 & 0,192 & $-0,020$ & 0,006 & $-0,001$ & 0,000 \\
\hline Gabão & 0,546 & 0,874 & $-0,115$ & 0,021 & $-0,002$ & 0,011 & $-0,002$ & 0,000 \\
\hline Gambia & 16,848 & 17,760 & $-1,189$ & 0,278 & 0,001 & 0,001 & 0,000 & 0,389 \\
\hline São Pedro e Miquelon & 111,905 & 37,875 & $-0,505$ & 0,833 & 0,004 & 0,003 & 0,000 & 0,394 \\
\hline Ruanda & 0,226 & 0,461 & 0,040 & 0,156 & $-0,051$ & 0,008 & $-0,001$ & 0,156 \\
\hline Camarões & 0,076 & 0,061 & 0,008 & 0,028 & $-0,094$ & 0,050 & $-0,010$ & 0,000 \\
\hline Qatar & 0,013 & 0,011 & $-0,002$ & 0,000 & $-0,017$ & 0,012 & $-0,003$ & 0,000 \\
\hline Congo & 0,047 & 0,021 & $-0,004$ & 0,000 & $-0,038$ & 0,024 & $-0,004$ & 0,001 \\
\hline Botsuana & 0,003 & 0,006 & 0,001 & 0,015 & $-0,002$ & 0,001 & 0,000 & 0,046 \\
\hline São Vicente e Granadinas & 1,885 & 0,592 & $-0,005$ & 0,889 & $-0,001$ & 0,000 & 0,000 & 0,754 \\
\hline Ilhas Virgens Britânicas & 0,717 & 0,953 & $-0,161$ & 0,001 & $-0,001$ & 0,003 & 0,000 & 0,231 \\
\hline Etiópia & 0,030 & 0,024 & 0,000 & 0,997 & 0,000 & 0,000 & 0,000 & 0,017 \\
\hline Zâmbia & 0,061 & 0,073 & $-0,011$ & 0,008 & $-0,011$ & 0,016 & $-0,003$ & 0,001 \\
\hline Camboja & 0,235 & 0,245 & $-0,042$ & 0,001 & 0,002 & 0,002 & 0,000 & 0,000 \\
\hline Líbano & 0,060 & 0,036 & 0,002 & 0,504 & $-0,036$ & 0,006 & $-0,001$ & 0,017 \\
\hline Barbados & 0,372 & 0,240 & $-0,047$ & 0,000 & $-0,008$ & 0,001 & 0,000 & 0,022 \\
\hline Síria & 0,036 & 0,068 & 0,009 & 0,021 & $-0,003$ & 0,003 & 0,000 & 0,127 \\
\hline Benin & 0,592 & 0,606 & $-0,107$ & 0,000 & $-0,018$ & 0,016 & $-0,003$ & 0,001 \\
\hline Burundi & 0,346 & 0,183 & $-0,022$ & 0,040 & 0,000 & 0,000 & 0,000 & 0,000 \\
\hline Nauru & 5,815 & 9,429 & $-1,137$ & 0,038 & 0,000 & 0,002 & 0,000 & 0,311 \\
\hline Dominica & 0,082 & 0,180 & $-0,007$ & 0,545 & $-0,001$ & 0,000 & 0,000 & 0,004 \\
\hline Libéria & 0,131 & 0,112 & 0,011 & 0,088 & $-0,002$ & 0,002 & 0,000 & 0,000 \\
\hline Moldova & 0,024 & 0,030 & $-0,004$ & 0,014 & $-0,015$ & 0,006 & $-0,001$ & 0,001 \\
\hline São Cristóvão e Nevis & 1,465 & 1,221 & 0,047 & 0,543 & 0,000 & 0,000 & 0,000 & 0,294 \\
\hline Níger & 1,130 & 1,543 & $-0,286$ & 0,000 & 0,001 & 0,003 & $-0,001$ & 0,000 \\
\hline Laos & 0,014 & 0,012 & $-0,001$ & 0,173 & $-0,001$ & 0,000 & 0,000 & 0,511 \\
\hline São Tomé e Príncipe & 1,399 & 3,819 & $-0,403$ & 0,075 & 0,000 & 0,000 & 0,000 & 0,003 \\
\hline Paraguai & 0,008 & 0,008 & $-0,001$ & 0,001 & $-0,001$ & 0,000 & 0,000 & 0,000 \\
\hline Azerbaijão & 0,012 & 0,018 & $-0,002$ & 0,050 & $-0,002$ & 0,001 & 0,000 & 0,000 \\
\hline Bolívia & 0,000 & 0,001 & 0,000 & 0,093 & $-0,002$ & 0,002 & 0,000 & 0,000 \\
\hline Quirguistão & 0,009 & 0,015 & 0,000 & 0,975 & $-0,003$ & 0,002 & 0,000 & 0,000 \\
\hline
\end{tabular}

Fonte: Elaborado pelos autores. 
Quanto ao IPR, os valores médios variaram de $-7,447$ a 3,936. Dos 143 países analisados, 72 obtiveram IPR $>0$, sendo, assim, exportadores líquidos. Destaque para a China, a Noruega, o Vietnã, a Índia, o Canadá, o Chile e a Indonésia, com IPR >1,0, o que reflete alta eficiência nas exportações. Na avalição temporal, 25 países apresentaram tendência crescente (e.g. China e Noruega), 49, estáveis (e.g. Vietnã e Indonésia) e 69, decrescentes (e.g. Japão e EUA).

De acordo com a matriz de desempenho (Quadro 3), 143 países exportadores de pescado foram classificados de acordo com os valores médios do IVCR e IPR,

Quadro 3. Matriz de desempenho dos países exportadores de pescado no comércio internacional durante o período de 2001 a 2016

\begin{tabular}{|c|c|c|c|c|}
\hline & Classificação & IVCR $>1$ & IPR $>0$ & \begin{tabular}{|c|} 
Países exportadores de pescado \\
\end{tabular} \\
\hline \multirow{9}{*}{ 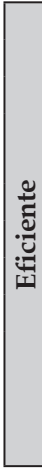 } & Crescente & $\pi$ & $\pi$ & Armênia - Equador - Noruega \\
\hline & \multirow{3}{*}{ Estável } & $\pi$ & $\leftarrow \rightarrow$ & Granada - Ilhas Feroe - Maldivas - Santa Helena \\
\hline & & $\leftarrow \rightarrow$ & $\pi$ & Cabo Verde - Chile - Grécia - Honduras - Índia - Peru \\
\hline & & $\leftarrow \rightarrow$ & $\leftarrow \rightarrow$ & $\begin{array}{l}\text { Belize - Croácia - Estônia - Gambia - Ilhas Malvinas - Ilhas Marshall - Malta - São } \\
\text { Cristóvão - São Pedro - Senegal - Sri Lanka }\end{array}$ \\
\hline & \multirow{5}{*}{ Decrescente } & $\pi$ & ע & Filipinas - Groelândia \\
\hline & & $\leftarrow \rightarrow$ & ע & Canadá - Guatemala - Samoa \\
\hline & & ע & $\pi$ & China - Nicarágua \\
\hline & & ע & $\leftarrow \rightarrow$ & Bangladesh - Indonésia - Namíbia - Somália - Vietnã \\
\hline & & ע & ע & $\begin{array}{l}\text { Argentina - Austrália - Bahamas - Colômbia - Coréia Norte - Costa Rica - Cuba - } \\
\text { Dinamarca - Guiana - Islândia - Quênia - Madagascar - Marrocos - Moçambique - } \\
\text { Nigéria - N. Caledônia - N. Zelândia - África Sul - Tailândia - Taipei Chino - Tanzânia } \\
\text { - Tunísia - Uganda - Uruguai }\end{array}$ \\
\hline & Classificação & IVCR $>1$ & IPR $<0$ & Países exportadores de pescado \\
\hline \multirow{9}{*}{ 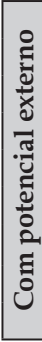 } & \multirow{3}{*}{ Crescente } & $\pi$ & $\pi$ & Jamaica - Portugal \\
\hline & & $\leftarrow \rightarrow$ & $\pi$ & Espanha - Ilhas Menores \\
\hline & & $y$ & $\pi$ & - \\
\hline & \multirow{3}{*}{ Estável } & $\pi$ & $\leftarrow \rightarrow$ & Lituânia - Mauricio - Polinésia Francesa - Suécia \\
\hline & & $\leftarrow \rightarrow$ & $\leftarrow \rightarrow$ & Chipre - São Vicente - Terras Austrais \\
\hline & & $y$ & $\leftarrow \rightarrow$ & Nauru \\
\hline & \multirow{3}{*}{ Decrescente } & $\pi$ & $y$ & Letônia \\
\hline & & $\leftarrow \rightarrow$ & ע & Haiti - São Tomé \\
\hline & & $y$ & $\pi$ & 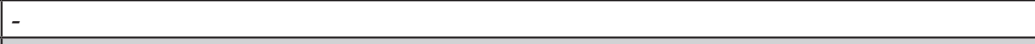 \\
\hline . & Classificação & IVCR $<1$ & IPR $>0$ & Países exportadores de pescado \\
\hline \multirow{9}{*}{ 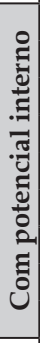 } & \multirow{3}{*}{ Crescente } & $\pi$ & $\lambda$ & Rússia - Turquia \\
\hline & & $\pi$ & $\leftarrow \rightarrow$ & Romênia - Trinidade \\
\hline & & $\pi$ & $y$ & Irlanda \\
\hline & \multirow{3}{*}{ Estável } & $\leftarrow \rightarrow$ & $\pi$ & República Checa \\
\hline & & $\leftarrow \rightarrow$ & $\leftarrow \rightarrow$ & Cazaquistão - Omã \\
\hline & & $\leftarrow \rightarrow$ & $y$ & Bahrein - Países Baixo \\
\hline & \multirow{3}{*}{ Decrescente } & 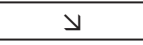 & $\pi$ & - \\
\hline & & $y$ & $\leftarrow \rightarrow$ & - \\
\hline & & $y$ & $\lambda$ & Camboja - México \\
\hline & Classificação & IVCR $<1$ & IPR $<0$ & Países exportadores de pescado \\
\hline \multirow{9}{*}{ 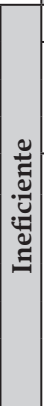 } & Crescente & $\pi$ & $\pi$ & Botsuana - Japão \\
\hline & \multirow{3}{*}{ Estável } & $\pi$ & $\leftarrow \rightarrow$ & Albânia - Alemanha - Bielorrússia - Eslovênia - Hungria - Luxemburgo - Síria \\
\hline & & $\leftarrow \rightarrow$ & $\pi$ & Bélgica - Dominica - EUA - Itália \\
\hline & & $\leftarrow \rightarrow$ & $\leftarrow \rightarrow$ & Costa Marfim - França - Hong Kong - Laos - Malaui - Reino Unido - Ruanda - Suíça \\
\hline & \multirow{5}{*}{ Decrescente } & $\pi$ & $y$ & Áustria - Camarões - Egito - Finlândia - Polônia \\
\hline & & $\leftarrow \rightarrow$ & ע & $\begin{array}{l}\text { Arábia Saudita - Bolívia - Bulgária - Eslováquia - Etiópia - Geórgia - Israel - Jordânia - } \\
\text { Quirguistão - Líbano - Libéria - Malásia - Ucrânia }\end{array}$ \\
\hline & & $y$ & $\pi$ & Barbados \\
\hline & & $y$ & $\leftarrow \rightarrow$ & Coréia do Sul - Ilhas Virgens \\
\hline & & ע & ע & $\begin{array}{l}\text { Argélia - Azerbaijão - Benim - Brasil - Burundi - Congo - El Salvador - Gabão - } \\
\text { Moldova - Paraguai - Catar - Singapura - Venezuela - Zâmbia }\end{array}$ \\
\hline
\end{tabular}

Fonte: Elaborado pelos autores. 
assim como a tendência destes valores no período de 2001 a 2016. Considerando a classificação de desempenho no mercado internacional para cada categoria, tem-se:

- Eficiente: 60 países localizados nos cinco continentes foram eficientes no comércio exterior, apresentando o pescado como pauta importante no contexto das exportações do país e com eficiência na venda do produto para o mercado externo. Destacam-se a Armênia, o Equador e a Noruega, que, além de serem eficientes, tiveram tendência dos índices IVCR e IPR crescentes. Observa-se, também, que dos 10 países que mais exportaram pescado em 2014, sete foram classificados como eficientes (China, Vietnã, Tailândia, Chile, Índia, Dinamarca e Canadá), em que a Noruega apresentou o melhor desempenho mundial. Os países classificados como "eficientes e decrescentes" necessitam de atenção, como é o caso da China, Nicarágua, Bangladesh, Indonésia, Namíbia, Somália e Vietnã, em que o pescado está perdendo importância na pauta das exportações. Para as Filipinas, Groelândia, Canadá, Guatemala e Samoa, por outro lado, a eficiência nas vendas do pescado para o exterior está decrescendo. O mesmo é válido para 24 países, que também necessitam de cuidado redobrado, pois tanto a exportação do pescado quanto a importância deste produto para cada país estão em decréscimo nas últimas décadas.

- Com potencial externo: 15 países apresentaram o pescado como pauta importante no contexto das exportações, mas que, no entanto, precisam avançar na eficiência da venda do pescado para o mercado externo. Assim, são países com potencial para obter melhor posição relativa no comércio exterior. Jamaica e Portugal mostram-se em recuperação, pois os índices foram crescentes ao longo do período. Nesta categoria, também está a Espanha, que apesar de ser um dos países que mais exportam, perdeu posição no comércio, mas com perspectiva de recuperação, pois os valores do IPR foram crescentes e os valores do IVCR estão estáveis. No entanto, Letônia, Haiti e São Tomé precisam avaliar o pescado no comércio exterior, porque, apesar de estarem classificados como "com potencial externo", tiveram tendência decrescente dos valores de IPR.

- Com potencial interno: 12 países apresentaram potencial para melhorar o status do pescado na pauta das exportações, ou seja, vantagem comparativa. Rússia, Turquia, Romênia, Trinidade e Tobago e Irlanda estão com maiores chances de sucesso, pois os índices IVCR e IPR foram crescentes, e Camboja e México, com poucas oportunidades, já que os índices apresentarem tendência decrescente.

- Ineficiente: 56 países foram ineficientes no comércio exterior, em que o pescado não é pauta importante no contexto das exportações do país. Desse modo, mostram-se como importadores líquidos de pescado. Botsuana e Japão apresentaram índices com tendência crescente, que podem modificar essa classificação. Os EUA, que são um dos maiores exportadores, apresentou-se como um importador em potencial. O subgrupo em destaque é o denominado "ineficiente e decrescente", pois, além de o pescado não ser importante na pauta de exportação, não há eficiência nas vendas, com ambos fatores decrescendo ao longo dos anos, como é o caso do Brasil.

\section{Discussão}

Em um ambiente cada vez mais globalizado, o comércio de pescado expandiu consideravelmente nas últimas décadas, impulsionado pela ampliação da produção pesqueira, principalmente da aquicultura e pela elevada procura. Deste modo, o pescado pode ser produzido em um país, processado em um segundo e consumido em um terceiro. Isto está associado ao aumento da terceirização do trabalho, que para países onde os salários e os custos de produção são comparativamente baixos, proporcionam vantagem competitiva.

De acordo com a FAO (2016), estima-se que 56,6 milhões de pessoas estavam envolvidas no setor primário da pesca e aquicultura em 2014, das quais 36\% estavam envolvidos em tempo integral, $23 \%$, em tempo parcial e o restante eram pescadores ocasionais ou não especificados. Depois de uma longa tendência ascendente, os números permaneceram relativamente 
estáveis desde 2010, enquanto a proporção destes trabalhadores envolvidos na aquicultura aumentou de 17\% em 1990 para 33\% em 2014. Em 2014, 84\% da população mundial envolvida na pesca e aquicultura era da Ásia, seguida da África (10\%) e América Latina e Caribe (4\%). Dos 18 milhões de pessoas envolvidas na piscicultura, 94\% são da Ásia.

Além deste aumento da força de trabalho, as políticas de liberalização do comércio, a globalização dos sistemas alimentares, a melhoria do transporte e da logística, as inovações tecnológicas e as alterações na distribuição e comercialização modificaram significativamente a forma como o pescado é preparado, processado e comercializado.

Diante disso, diversos fatores contribuem para aumentar a competição entre os países, como as crescentes exigências dos consumidores com relação à qualidade do produto, o estabelecimento de políticas protecionistas e de subsídios, a existência de barreiras tarifárias e não tarifárias, o desenvolvimento e a inovação tecnológica, os mecanismos de comercialização adotados pelas empresas e os investimentos em estratégias de marketing e propaganda.

De acordo com os resultados da presente pesquisa, dentre os países classificados como eficientes, o excelente desempenho da Noruega pode ser explicado pela diversificação dos produtos e ampliação do comércio para diversos países. Segundo dados do ITC, a Noruega comercializa, principalmente, quatro tipos de produtos: peixe fresco, peixe congelado, filé de peixe e peixe seco. Os principais peixes frescos exportados são: salmão (Salmo salar), truta (Oncorhynchus spp.), bacalhau (Gadus morhua), eglefin (Melanogrammus aeglefinus), verdinho (Micromesistius poutassou), arenque (Clupea spp.), halibut (Hippoglossus spp.), paloco (Pollachius virens), cavala (Scomber spp.), solha (Psetta máxima) e merluza (Pleuronectes platessa). Os principais países importadores deste produto são: Dinamarca, França, Federação Russa e Polônia. Em relação ao peixe seco, o bacalhau é o item mais exportado, principalmente para Portugal. Para o peixe congelado destacam-se a cavala, o arenque, o salmão, o eglefin, o bacalhau e a truta e, para o filé de peixe, o salmão e o arenque. Os principais compradores de peixe congelado são: Japão, Federação Russa e China e, de filé de peixe são: França, Reino Unido, Alemanha e EUA. O mesmo cenário pode ser observado para outros países, como China, Dinamarca, Tailândia, Vietnã, Índia, Chile e Canadá.
Em contraponto, dentre os países classificados como ineficientes, foram encontrados os EUA e o Japão, que apesar de estarem entre os maiores exportadores do mundo, são importadores líquidos, mas com níveis crescentes e estáveis de exportação. Cenário diferente é observado para o Brasil, que, além de ser ineficiente, tem níveis de comercialização decrescentes.

Revisando as informações sobre as relações de comércio exterior do Brasil, estas fazem referência especialmente a estudos relacionados aos produtos agropecuários. No caso do pescado, os resultados das pesquisas publicadas indicam que o Brasil necessita avançar na produção e melhorar o desempenho na comercialização deste produto tanto para o mercado interno quanto para o externo (e.g CARDOSO et al., 2013; LOZANO et al., 2014; BARBOSA, 2015; SANTOS et al., 2015; SONODA et al., 2015; BRABO et al., 2016).

Assim como no mundo, o consumo de pescado no Brasil também aumentou nos últimos anos. Em 1996, a média per capita foi de 7,5 kg e em 2011 de $11,2 \mathrm{~kg}$, com estimativa de $12 \mathrm{~kg}$ em 2015. No entanto, o Brasil está recorrendo às importaçóes para atender à procura. A balança comercial entre as exportações e importações de pescado mostrou que, de 1998 a 2000 houve um déficit de aproximadamente de 160 milhões de dólares/ano, que foi recuperado no período subsequente até 2005, com superávit de 132 milhões de dólares/ano. No entanto, a partir de 2006, a importação de pescado apresentou crescimento gradativo e superior às exportações, com consequente taxa de cobertura decrescente ao longo dos últimos 10 anos, o que significa que o Brasil está com um grau alto de dependência com o mercado externo. Em 2015, os gastos com importação foram de 1,1 bilhão de dólares, principalmente de produtos que não são produzidos no Brasil, como o bacalhau, o salmão e a merluza, o que ocasionou déficit de $80 \%$ na balança comercial de pescado (ROCHA et al., 2013).

Essa dinâmica de comércio refletiu nas empresas de pescado com maior quantidade de importadoras do que exportadoras. Em 2015, de acordo com as estatísticas do comércio exterior (ITC), no Brasil existem 57 empresas exportadoras de pescado, sendo 18 na região Nordeste, 18 no Sudeste, 16 no Sul, quatro no Norte e uma no Centro-Oeste, distribuídas em 12 estados e 29 cidades. Quanto à importação de pescado, o Brasil tem 89 empresas importadoras, sendo 44 na região Sudeste, 20 no Sul, 18 no Nordeste, qua- 
tro no Centro-Oeste e três no Norte, distribuídas em 14 estados e 47 cidades.

Kirchner et al. (2016), Ostrensky et al. (2008) e Yamaguchi et al. (2008) citam vários problemas deste setor, como: (I) falta de políticas públicas para o desenvolvimento e consolidação da atividade; (II) falta de treinamento e qualificação técnica ao longo de toda a cadeia produtiva; (III) dificuldade de acesso ao crédito para investimento e custeio; (IV) necessidade de aumento da competitividade em pequena e média escala; (V) necessidade de viabilização, em escala industrial, do processamento dos produtos de pescado; (VI) necessidade de criação de um sistema nacional de controle da sanidade aquícola; (VII) necessidade de conquista de novos mercados e consumidores; (VIII) necessidade de agilização da regularização ambiental dos empreendimentos, em especial em águas de domínio da união; (IX) necessidade de levantamento e divulgação de informações setoriais básicas e $(X)$ necessidade de desenvolvimento, validação e replicação de modelos sustentáveis de produção adaptados às diferentes espécies de pescado e regiões do País. Assim, estes problemas comprometem a produção em escala de pescados, reduzindo a oferta para o nível local quanto à capacidade de competir no comércio exterior.

Nos últimos dez anos, os padrões do comércio internacional se moveram a favor do comércio entre países desenvolvidos e em desenvolvimento. Os países desenvolvidos ainda comercializam principalmente entre si. No entanto, nas últimas três décadas, a participação das suas exportações para os países em desenvolvimento aumentou, também devido à terceirização da transformação de sua produção pesqueira. Ao mesmo tempo, enquanto os países desenvolvidos continuam sendo seus principais mercados, os países em desenvolvimento aumentaram o comércio entre si.

A elevada dependência das importações para satisfazer o consumo interno dos países desenvolvidos é uma das principais razões para as suas baixas tarifas de importação de peixe, especialmente para os três maiores mercados de importação, a União Europeia, os EUA e o Japão. Isso permitiu aos países em desenvolvimento fornecerem pescado aos mercados dos países desenvolvidos sem enfrentar direitos aduaneiros proibitivos. Esta tendência decorre da expansão da composição da Organização Mundial do Comércio (OMC) e da entrada em vigor de uma série de acordos comer- ciais bilaterais e multilaterais. No entanto, muitos países em desenvolvimento continuam a aplicar tarifas de importação elevadas para o pescado, e embora isso normalmente reflita a política fiscal em vez de ser uma medida de proteção, tem efeitos prejudiciais sobre o comércio regional (RANI e KUMAR, 2016).

Às vezes, as barreiras mais importantes que os países em desenvolvimento enfrentam para aumentar suas exportações para os países desenvolvidos relacionam-se mais à capacidade de satisfazer necessidades de importação em constante evolução. Estes incluem áreas como qualidade e segurança, mas estão cada vez mais relacionados com as normas técnicas e com a rotulagem e, mais recentemente, com a certificação voluntária para a sustentabilidade biológica, bem como com as condições sociais e laborais dentro da indústria e seus fornecedores (GEPHART e PACE, 2015).

Algumas destas exigências de importação são reguladoras e, portanto, vinculativas. No entanto, as empresas privadas estão cada vez mais definindo as suas próprias especificações que os produtores têm de cumprir. Outros impactos sobre o comércio nos países em desenvolvimento podem estar ligados a barreiras técnicas ao comércio, que se referem a regulamentações técnicas e normas que definem características específicas de um produto. O Acordo da OMC sobre Obstáculos Técnicos ao Comércio contém regras que visam expressamente evitar que essas medidas se tornem barreiras desnecessárias, mas elas ainda existem e criam dificuldades para os comerciantes.

De acordo com Asche et al. (2015), o comércio internacional de pescado não é justo para os países em desenvolvimento, pois o intercâmbio de qualidade é diferente: os países em desenvolvimento exportam pescados de alta qualidade em troca de pescado de baixa qualidade.

\section{Conclusão}

Na dinâmica do comércio internacional de pescado, a eficiência se deve, em geral, aos países desenvolvidos, que comercializam o pescado principalmente entre si. Esse intercâmbio é bem variado tanto em produtos quanto em países. No entanto, a participação das suas exportações para os países em desenvolvimento aumentou também devido à terceirização da transfor- 
mação de sua produção pesqueira. Ao mesmo tempo, enquanto os países desenvolvidos continuam sendo seus principais mercados, os países em desenvolvimento também aumentaram o comércio entre si.

No caso do Brasil, o desempenho da comercialização é ineficiente e decrescente, pois o pescado não é pauta importante no conjunto das exportações brasileiras, assim como o País é inábil na venda do produto para o mercado externo. Desse modo, o pescado brasileiro não tem servido como uma estratégia de crescimento econômico para o setor pesqueiro e aquícola, utilizando-se dos comércios internacional e local.

Assim, dada a importância alimentícia e comercial do pescado no mundo e no Brasil, os gestores poderiam expandir a produção aquícola brasileira com maiores investimentos nas áreas de pesquisa, tecnologia, desenvolvimento e inovação para que se possa atender, a priori, o mercado local. Estas ações sobre as atividades do mercado interno podem aumentar e/ou criar serviços, gerando emprego e renda para a população, como estratégia de crescimento econômico e com vistas às exportações.

\section{Referências}

ASCHE, F. et al. Fair enough? Food security and the international trade of seafood. World Development, v. 67, p. 151-160, 2015.

BALASSA, B. Trade liberalisation and "revealed" comparative advantage. The Manchester School, v. 33, n. 2, p. 99-123, 1965.

BARBOSA, J. M. Fraudação na comercialização do pescado. Acta of Fisheries and Aquatic Resources, v. 3, n. 2, p. 89-99, 2015.

BRABO, M. F. et al. Cenário atual da produção de pescado no mundo, no Brasil e no estado do Pará: ênfase na aquicultura. Acta of Fisheries and Aquatic Resources, v. 4, n. 2, p. 50-58, 2016.

CARDOSO, E. S., LEAL, C. L. C. e COSTA, J. M. O mercado e o pescado: uma primeira atualização dos circuitos econômicos e das cadeias produtivas do peixe em Santa Maria - RS. Ciência e Natura, v. 35, n. 2, p. 226231, 2013.

ESPERANÇA, A. A., LÍRIO, V. S. e MENDONÇA, T. G. Análise comparativa do desempenho exportador de flores e plantas ornamentais nos estados de São Paulo e Ceará. Revista econômica do Nordeste, v. 42, n. 2, p. 259286, 2011.

FAO. The state of world fisheries and aquaculture. Rome: FAO, 2010, $197 \mathrm{p}$.

. The state of world fisheries and aquaculture: contributing to food security and nutrition for all. Rome: FAO, 2016, 204 p.

GEPHART, J. A. e PACE, M. L. Structure and evolution of global seafood trade network. Environmental Reserarch Letters, v. 10, p. 1-11, 2015.

GONÇALVES, R. R. et al. Economia internacional. Rio de Janeiro: Editora FGV, 2013, 156p.

GUJARATI, D. N. e PORTER, D. C. Econometria básica. 5. ed. São Paulo: Amgh Editora, 2011, 920 p.

KIRCHNER, R. M. et al. Análise da produção e comercialização do pescado no Brasil. Revista Agroambiente Online, v. 10, n. 2, p. 168-177, 2016.

LAFAY, G. et al. Nations et mondialisation. Paris: Economica, 1999. $410 \mathrm{p}$.

LOZANO, B. S. et al. Qualidade e segurança agroalimentar: a influência do transporte na qualidade do peixe. Revista da Universidade Vale do Rio Verde, v. 12, n. 1, p. 238-247, 2014.

MOREIRA, U. Teorias do comércio internacional: um debate sobre a relação entre crescimento econômico e inserção externa. Revista de Economia Política, v. 32, n. 2, p. 213-228, 2012.

MUNDURUCA, D. F. V. e SANTANA, J. R. Comércio exterior como estratégia de crescimento econômico: uma proposta de priorização de produtos exportáveis para a economia sergipana. Revista econômica do Nordeste, v. 43, n. 3, p. 611-630, 2012.

NORTH, D. Location Theory and Regional Economic Growth. Journal of political economy, v. 63, n. 3, p. 243258, 1955.

OSTRENSKI, A., BORGHETTI, J. R. e SOTO, D. Aquicultura no Brasil: o desfaio é crescer. Brasília: FOAO/ MPA, 2008, 276 p.

PAIS, P. S. M., GOMES, M. F. M. e COROMEL, D. A. Análise da competitividade das exportações brasileiras de minério de ferro, de 2000 a 2008. Revista de Administração Mackenzie, v. 13, n. 4, p. 121145, 2012.

RANI, P. e KUMAR, N. R. Status and competitiveness of fish exports to European Union. Fishery Technology, v. 53, p. $69-74,2016$. 
ROCHA, C. M. C. et al. Avanços na pesquisa e no desenvolvimento da aquicultura brasileira. Pesquisa Agropecuária Brasileira, v. 48, n. 8, p. iv-vi, 2013.

SANTOS, E. L. N. et al. A logística na exportação da indústria do pescado no Rio Grande do Norte. Empirica, v 8, n. 1, p. 55-66, 2015.

SARTORI, A. G. O. e AMANCIO, R. D. Pescado: importância nutricional e consumo no Brasil. Segurança alimentar e nutricional, v. 19, n. 2, p. 83-93, 2012.
SONODA, D. Y. et al. Desequilíbrio entre a oferta e a demanda brasileira por pescados em 2002/2003 e 2008/2009. Revista iPecege, v. 1, n. 1, p. 9-21, 2015.

USDA. Livestock and poultry: world markets and trade. Disponível em: <https://apps.fas.usda.gov/psdonline/ circulars/livestock_poultry.pdf > . Acesso em: 5 abr. 2017. YAMAGUCHI, M. M., BARRETO, L. E. G. S. e IGARASHI, M. A. Estrategias para o desenvolvimento da aquicultura no Brasil. UNOPAR Científica: Ciências exatas e Tecnológicas, v. 7, p. 13-24, 2008.

Todo o conteúdo deste periódico, exceto onde estiver identificado, está licenciado sob uma Licença Creative Commons (cc by 4.0). 